UCRL-ID-133200

\title{
Methods for Determining the Height of the Atmospheric Boundary Layer
}

Gayle Sugiyama

John S. Nasstrom

February 1, 1999

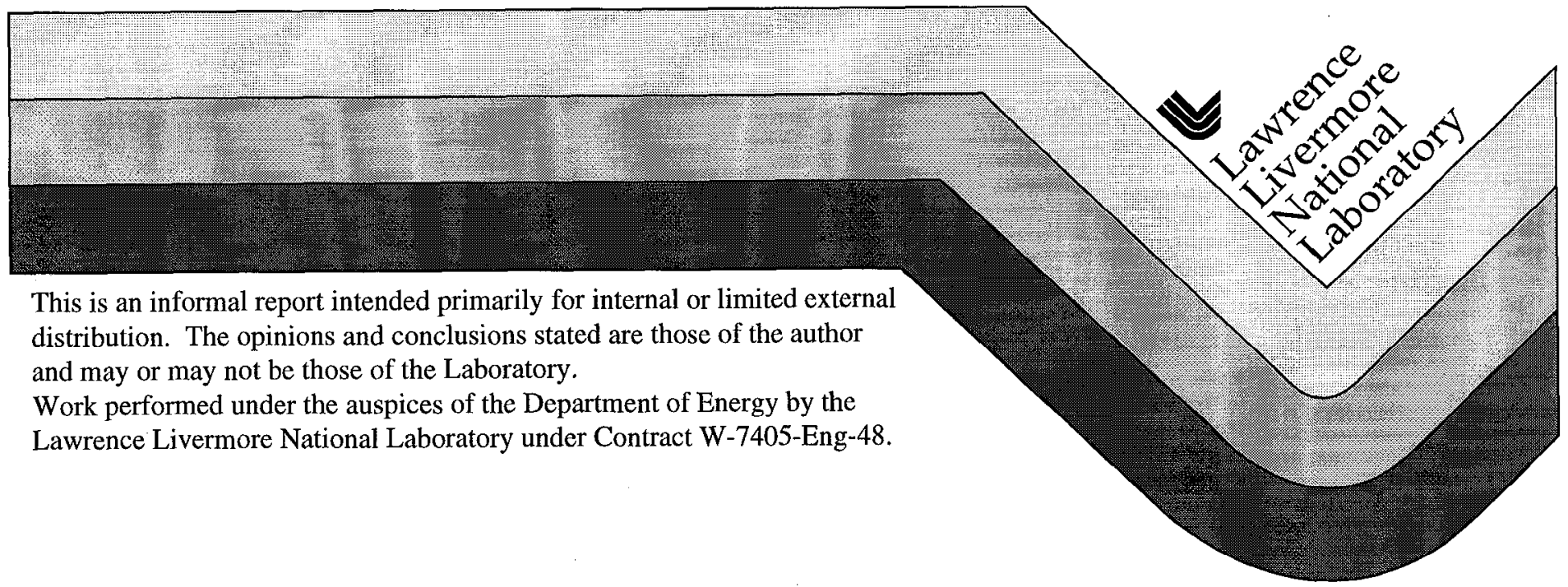




\section{DISCLAIMER}

This document was prepared as an account of work sponsored by an agency of the United States Government. Neither the United States Government nor the University of California nor any of their employees, makes any warranty, express or implied, or assumes any legal liability or responsibility for the accuracy, completeness, or usefulness of any information, apparatus, product, or process disclosed, or represents that its use would not infringe privately owned rights. Reference herein to any specific commercial product, process, or service by trade name, trademark, manufacturer, or otherwise, does not necessarily constitute or imply its endorsement, recommendation, or favoring by the United States Government or the University of California. The views and opinions of authors expressed herein do not necessarily state or reflect those of the United States Government or the University of California, and shall not be used for advertising or product endorsement purposes.

This report has been reproduced directly from the best available copy.

Available to DOE and DOE contractors from the Office of Scientific and Technical Information

P.O. Box 62, Oak Ridge, TN 37831

Prices available from (615) 576-8401, FTS 626-8401

Available to the public from the

National Technical Information Service

U.S. Department of Commerce

5285 Port Royal Rd.,

Springfield, VA 2216 


\title{
METHODS FOR DETERMINING THE HEIGHT OF THE ATMOSPHERIC BOUNDARY LAYER
}

\author{
G. Sugiyama and J. S. NaSSTrom
}

The $\Lambda$ tmospheric Release Advisory Capability (ARAC) is an operational emergency response program which provides real-time dose assessments of airborne pollutant releases. This report reviews methodologies for determining the height of the atmospheric boundary layer (ABL), which were investigated for use in the next generation of ARAC diagnostic and dispersion models. The $\mathrm{ABL}$ height, $h_{\mathrm{ABL}}$, is an essential parameter in atmospheric dispersion modeling, controlling the extent of the vertical mixing of pollutails near the surface. Although eventually instrumentation (radiosonde, lidar, sodar, etc.) may provide accurate means for determining $h_{\mathrm{ABL}}$, at present the availability of such data is too limited to provide a general capability for ARAC.

The current operational ARAC diagnostic models use a fixed value of $h_{\mathrm{ABL}}$ for any given time. ARAC's new models support a horizontally-varying atmospheric boundary layer height, which is used to generate meteorological (mean wind, temperature, etc.) and turbulence fields. The purpose of the present work is to develop methods to derive the ABL height for all atmospheric stability regimes. One of our key requirements is to provide approaches which are applicable to routinely available data, which may be of limited temporal and spatial resolution. The final objective is to generate a consistent set of meteorological and turbulence or eddy diffusivity fields to drive the new ARAC dispersion model.

A number of alternative definitions of the atmospheric boundary layer exist, leading to different approaches to deriving $h_{\mathrm{ABL}}$. The definitions are based on either the turbulence characteristics of the atmosphere or the vertical structure of one or more meteorological variables. Most diagnostic analyses determine $h_{\mathrm{ABL}}$ from profiles of temperature or occasionally wind. A class of methods of considerable current interest are based on Richardson number criteria. Prognostic methods calculate the time evolution of the top of the $\mathrm{ABL}$ from a rate equation. A number of commonly used methods of both types are reviewed below along with considerations on their applicability to various types of meteorological data and atmospheric conditions.

\section{TEMPERATURE PROFILE METHODS}

A variety of methods have been proposed for diagnosing the depth of the atmospheric boundary layer based on the vertical temperature structure. Holzworth (1967) calculated maximum mixing layer depths from morning temperature soundings and maximum afternoon surface temperatures assuming a dry-adiabatic lapse rate - a method often used in air quality modeling studies. Other authors have defined $h_{\mathrm{ABL}}$ as the height to which significant cooling extends in the nocturnal boundary layer (Yamada, 1979), the height of the lowest discontinuity in the temperature profile (Hanna, 
1969), or the top of a linear potential temperature layer (Wetzel, 1982).

\subsection{Critical Temperature Inversion}

A method originally developed by Heffter (1980) analyzes potential temperature profiles for the existence of a critical elevated inversion, which is assumed to indicate the top of the ABL. The inversion is identified as the height $z$ at which the potential temperature lapse rate and the temperature difference between the inversion base and top meet the following criteria

$$
\begin{aligned}
\Delta \theta / \Delta z & \geq 0.5^{\circ} \mathrm{K} / 100 \mathrm{~m} \\
\Delta \theta & >2^{\circ} \mathrm{K}
\end{aligned}
$$

where $\theta$ is the potential temperature. The top of the ABL is then specified to be the height within the critical inversion layer for which the temperature is $2^{\circ} \mathrm{K}$ above the temperature at the inversion base.

Numerous authors have modified and refined Heffter's thermal inversion criteria. AFTAC's POTEMP model (Kienzle, 1985) introduces five potential temperature lapse rates and difference criteria, leading to set of possible values for $h_{\mathrm{ABL}}$. The ABL height is then taken to be the lowest of these values which differs from the next greatest height by more than $200 \mathrm{~m}$. In the PIMIX code (Kienzle, 1990), the critical inversion is determined to occur when the observed lapse rate is more than $0.001 \mathrm{~K} / \mathrm{m}$ less than the moist adiabatic lapse rate. Additional tests are used to ensure that the identified inversions arc of sufficient strength to form a cap to vertical mixing.

Temperature inversion methods rely on the specification of a somewhat subjective lapse rate criteria to identify the thermal inversion. For any given sounding, it can be difficult to locate an inversion due to noise in the data or insuficient vertical resolution to resolve details of the ABL structure. This is particularly true in situations involving weak surface heating, complex synoptic flow, or a poorly defined capping inversion. The application of thermal inversion height criteria to numerical model data can also be problematic due to numerical smoothing of field gradients.

\section{METHODS BASED ON SURFACE FLUXES}

A significant increase in our understanding of the ABL has occurred over the last decades, particularly for the convective boundary layer. This has lead to the development of slab (also known as jump or integral) models, which solve a rate equation for the daytime growth of the unstable boundary layer depth. For neutral to stable conditions, a number of expressions based on similarity theory exist for estimating the top of the ABL. Van Ulden and Holtslag (1985) review several of these methods.

A major advantage of surface flux based methods is the relatively limited data required surface momentum and heat fluxes and surface-layer scaling parameters, such as the friction velocity 
$u_{*}$ and the Monin-Obukhov length $L$. These quantities can be derived from readily available surface observations using the similarity flux-profile equilibrium relations discussed in Appendix $\mathbf{A}$.

\subsection{Neutral to Stable Conditions}

For near-neutral conditions, the mechanical ABL depth (Blackadar and Tennekes, 1968) can be calculated from

$$
h_{\mathrm{ABL}}=\frac{c_{n} u_{*}}{|f|} \quad \text { when } \quad\left|\frac{u_{*}}{f L}\right|<4
$$

where $f=2 \Omega \sin \phi$ is the Coriolis parameter, $\phi$ is the latitude, and $\Omega=7.292 \times 10^{-5} \mathrm{rad} / \mathrm{s}$. Since this equation yields unrealistic values for small $\phi$ (i.e. the tropics), a minimum value of $\phi \approx$ $20^{\circ}=0.35 \mathrm{rad}$ should be used. Blackadar and Tennekes set the proportionality constant $c_{n}=0.2$. However, othei authors advocate values between 0.07 and 0.5 , which ieads to systematic differences in the estimate of $h_{\mathrm{ABI}}$ (Wotawa et al., 1996). It should also be noted that if the height of an elevated inversion is known, it should be used instead of the above formula.

For stable conditions, the height of the boundary layer can be calculated from Zilitinkevich's (1972) expression,

$$
h_{\mathrm{ABr}}=c_{s}\left(\frac{u_{*} L}{|f|}\right)^{\frac{1}{2}} \quad \text { when } \quad\left|\frac{u_{*}}{f L}\right|>4
$$

where $c_{s}=0.4$. If the condition is violated, the neutral formula of the preceding paragraph is used instead. Since the Zilitinkevich formula predicts small values (tens of meters) for $h_{A B L}$ in very stable conditions, it may also be necessary to set a minimum value of $h_{\mathrm{ABS}}$.

An alternative expression due to Nieuwstadt (1981) combines these two relationships for the ABL height to yield

$$
h_{\mathrm{ABL}}=\frac{c_{1} u_{*} /|f|}{1+c_{2} h_{\mathrm{ABI}} / L}
$$

This equation reduces to the neutral and stable forms as $L \rightarrow \infty$ and $L \rightarrow 0$ respectively, if the constants $c_{1}$ and $c_{2}$ are set appropriately, and provides a continuous transition between stable and neutral conditions. Nieuwstadt (1981) used $c_{1}=0.3$ and $c_{2}=1.9$, but to match the formulae in Van Ulden and Holtslag (1985) $c_{1}=0.2$ and $c_{2}=1.25$.

Recent work indicates that the ABL formulae based on surface layer and Coriolis parameters are not very satisfactory (Vogelezang, 1996; Seibert, 1997). However, in the absence of sufficient data to determine $h_{\mathrm{ABI}}$, by other means, they may provide the only possible estimates.

\subsection{Unstable, Convective Conditions : Slab Model}

Slab models (Tennekes, 1973; Carson, 1973) have been developed to describe the rate of growth of the daytime unstable boundary layer, for which diagnostic expressions have so far proved unsatisfactory. These models assume that mean values of variables such as the temperature are constant 
with height within the unstable boundary layer and that the entrainment layer can be represented as a infinitesimally thin layer across which there is a discontinuous jump in the value of a variable. The effects of latent heating, horizontal advection, divergence of the radiation heat flux, and large-scale vertical velocities are treated as negligible.

When buoyancy-generated turbulence is dominant, the rate equation for the convective $h_{\mathrm{ABC}}$ is given by

$$
\frac{d h_{\mathrm{ABL}}}{d t}=(2 \beta+1) \frac{\overline{w^{\prime} \theta_{o}^{\prime}}}{\gamma h_{\mathrm{ABL}}}
$$

where $\beta=0.2$ and $\gamma=\frac{\partial \theta}{\partial z}$ is the potential temperature gradient above $h_{\mathrm{ABL} L}$. This expression is based on the assumptions that the heat flux varies linearly with height and the entrainment heat flux at $z=h_{\mathrm{ABI}}$ is proportional to the surface heat flux $\overline{w^{\prime} \theta_{h}^{\prime}}=-\overline{\beta w^{\prime} \theta_{o}^{\prime}}$.

Mechanically-generated shear turbulence is dominant when the the surface lieat flux is zero. - In this case, assuming once again a linear variation of heat flux wich height and specifying the entrainment heat flux at $z=h_{\mathrm{ABL}}$ as $\overline{w^{\prime} \theta_{h}^{\prime}}=-\frac{\alpha \theta u_{z}^{3}}{g h_{\mathrm{ABI}}}$, the rate equation for $h_{\mathrm{ABL}}$ becomes

$$
\frac{d h_{\mathrm{ABL}}}{d t}=2 \alpha \frac{\theta}{g} \frac{u_{*}^{3}}{\gamma h_{\mathrm{ABL}}{ }^{2}}
$$

where $\alpha=2.5$.

Given initial values for $h_{\mathrm{ABI}}$, these two rate equations may be integrated to determine the time evolution of $h_{\mathrm{ABL}}$. For the general case, van Dop et al. (1997) proposed the interpolation formula

$$
h_{\mathrm{ABL}}=\left(h_{m}^{3}+h_{b}^{3}\right)^{1 / 3}
$$

where $h_{m}$ and $h_{b}$ are the boundary layer depths determined for the limiting cases of purely mechanically or buoyancy-generated turbulence, respectively.

The slab approach has been used extensively in air pollution and dispersion modeling due to its efficiency and simplicity (Sykes, 1996; EPA, 1995). The method assumes that the vertical distribution of potential temperature within the boundary layer is uniform with a strong capping inversion. The weaknesses of the approach are the singular behavior of the formula as $\gamma \rightarrow 0$, which causes over-prediction of $h_{\mathrm{ABL}}$ for small lapse rates, and its inability to treat the nocturnal boundary layer.

\section{$3 \quad$ RICHARDSON NUMBER}

The Richardson number, $\mathrm{Ri}$, is defined as the ratio of buoyancy to shear production of turbulence and provides a measure of the dynamic stability of the flow. Since onc definition of the ABL identifies it as the layer in which turbulent mixing occurs due to the presence of the ground, $h_{\mathrm{ABL}}$ can be specified to be the height at which the Richardson number exceeds a critical value. 


\subsection{Gradient Richardson Number}

The gradient Richardson number is defined as

$$
\mathrm{Ri}=\frac{\frac{g}{\theta_{v}}\left(\frac{\partial \theta_{v}}{\partial z}\right)}{\left[\left(\frac{\partial u}{\partial z}\right)^{2}+\left(\frac{\partial v}{\partial z}\right)^{2}\right]}
$$

where $\theta_{v}$ is the virtual potential temperature, $z$ is the height, and $u$ and $v$ are the horizontal wind velocity components. Two dynamic stability criteria are associated with the Richardson number : laminar flow becomes turbulent when $\mathrm{Ri}<\mathrm{R}_{\mathrm{c}}$ and turbulent How becomes laminar when $\mathrm{Ri}>\mathrm{R}_{\mathrm{T}}$. Values for the critical limits based on theoretical and laboratory research are $R_{C}=0.21-0.25$ and $R_{T}=1.0$ (Stull, 1988). The Richardson number must be lowered to $R_{c}$ before the onset of turbulence, but developed turbulence can persist until the Richardson number exceeds $R_{\mathrm{T}}$.

The top of the boundary layer can be determined by searching from the surface upwards, calculating gradients between successive levels, until the critical Richardson number is exceeded. This approach requires highly-resolved vertical temperature and wind data so that the derivatives can be computed accurately, a condition that is not commonly met by either observational profiles or forecast model data. The Richardson number calculated in this manner is sensitive to small changes in the temperature profiles. The smoothing out of the gradients produced by using finite differences also results in the need to use larger critical $R_{1}$ values than can be justified theoretically (Stull, 1988). As an example, a recent application found that using an ABI, criteria of $R_{c}=0.25$ underestimated the boundary layer height, while values near 0.55 produced reasonable results depending on the thickness of the sucessive layers (Straume et al., 1998).

\subsection{Bulk Richardson Number}

For stable conditions, the ABL height can be determined from the critical bulk Richardson number $\mathrm{Ri}_{\mathrm{B}}^{\mathrm{C}}$, defined as a constant value across the entire boundary layer (Hanna, 1969) :

$$
h_{\mathrm{ABL}}=\operatorname{Ri}_{\mathrm{B}}^{\mathrm{c}} \frac{\left(u_{h}^{2}+v_{h}^{2}\right)}{\left(g / \theta_{v 0}\right)\left(\theta_{v h}-\theta_{v 0}\right)}
$$

where $\theta_{v h}$ and $\theta_{v 0}$ are the virtual potential temperatures at the top of the boundary layer and the surface respectively, $u_{h}$ and $v_{h}$ are the horizontal wind components at $h_{\mathrm{ABL}}$, and $g$ is the gravitational acceleration. This formulation reduces sensitivity to the possible existence of internal stable layers within than ABL. The choice of the critical value for $\mathrm{Ri}_{\mathrm{B}}^{\mathrm{c}}$ which defines the top of the boundary layer varies somewhat in the literature. Mahrt (1981) used a value of $\mathrm{Ri}_{\mathrm{B}}^{\mathrm{c}}=0.5$, while Wetzel (1982) found an optimal choice to be $\mathrm{Ri}_{\mathrm{B}}^{\mathrm{c}}=0.33$ for the stable boundary layer, and Sørenson et al. (1996) identified 0.24 as the best value for a long-range transport case. Vogelezang and Holtslag (1996) investigated the bulk critical Richardson number approach and found it to be superior to either of the scaling theory formulations described in Section 2.1. 
A general formulation for $h_{\mathrm{ABL}}$ applicable to all stability conditions (Holtslag et al., 1995; Vogelezang and Holtslag, 1996) is given by

$$
h_{\mathrm{ABL}}-z_{1}=\operatorname{Ri}_{\mathrm{VH}}^{c} \frac{\left(u_{h}-u_{1}\right)^{2}+\left(v_{h}-v_{1}\right)^{2}+b u_{*}^{2}}{g / \theta_{v 1}\left[\theta_{v h}-\theta_{v s}\right]}
$$

where $u_{1}, v_{1}$, and $\theta_{v 1}$ are the wind components and virtual potential temperature at the height $z_{1}$. The inclusion of these terms improves the estimate of the Richardson number by determining shear production from the region of the $\mathrm{ABL}$ above the surface layer. The $b u_{*}^{2}$ term accounts for turbulence production due to surface friction, which is non-negligible for neutral boundary layers in which both elevated shear and buoyancy contributions may be small. The constant $b$ has been determined to be approximately 100 from LES and E- $\epsilon$ turbulence closure models. The definition of $\theta_{v s}$ incorporates the effect of convective parcels (Troen and Mahrt, 1986) :

$$
\theta_{v s}=\theta_{v}(s)+\theta_{T}=\theta_{v}(s)+c \frac{\left(\overline{w^{\prime} \theta_{v}{ }^{\prime}}\right)_{0}}{w_{m}}
$$

where $\theta_{v}(s)$ is the virtual potential temperature at the surface $s$ and $\theta_{T}$ is an excess temperature which includes the effect of convective thermals in the boundary layer. The constant $c$ is set to 8.5, $w_{n}$ is a turbulent velocity scale, and $\overline{w^{\prime} \theta_{v}{ }^{\prime}}$ is the buoyancy fux at the surface. For the unstable or convective case, the second term dominates and the ABL depth is insensitive to the choice of the critical Richardson number. As the surface fluxes weaken and neutral conditions are approached, the temperature excess vanishes so that $\theta_{v s} \rightarrow \theta_{v}(s)$ and the boundary layer height formula reduces to the stable equation of the previous paragraph. This ensures a smooth transition from unstable to stable conditions.

In practice, the Richardson number is computed using all model or observational levels greater than $z_{1}$ until the critical value is exceeded. The value of $h_{\mathrm{ABL}}$ is then determined by linear interpolation between that level and the next lowest one. The use of the bulk Richardson number to diagnose $h_{\mathrm{ABL}}$ has recently been shown to yield good results for a variety of atmospheric conditions, with the results relatively insensitive to the exact choice of $z_{1}$. The results do depend on the choice of the critical number, although values of $\mathrm{Ri}_{\mathrm{vH}}^{c}=0.25-0.30$ are common. The main weaknesses of the Richardson number approach are the requirement for sufficiently resolved vertical profiles of wind and temperature and the uncertainty in the optimal value of $\mathrm{Ri}_{\mathrm{VH}}^{c}$.

\section{OTHER METHODS}

Numerous other approaches to cstimating the height of the atmospheric boundary laycr can be found in the literature. Apart from temperature based methods, $h_{\mathrm{ABL}}$ can be determined from vertical wind profile criteria, using definitions such as the height of the maximum in the low-level wind speed, the height of the maximum east-wind wind speed, or the lowest level of negligible vertical wind shear. Stull and Driedonks (1987) inferred the depth of the ABL from the height at which a rising parcel of surface layer air first becomes neutrally buoyant. Beljaars and Betts (1992) also used a lifting parcel method which includes the calculation of an excess eddy temperature at the surface from temperature profiles, $u_{*}$, and the sensible surface heat flux. 
Methods for diagnosing the depth of the boundary layer are based on identifying a feature in the vertical structure of an observable variable which robustly identifies the vertical extent of turbulent or thermal effects due to the surface. The degree to which any method is successful depends on the availability and resolution of data (observations or model generated fields) and the atmospheric conditions. Even when data is available, the ABL may contain complicated structures, such as internal thermal boundary layers, which makes precise definition of the top of the layer difficult. The determination of the nocturnal boundary layer is perhaps the most problematic, since the height of the turbulent layer, the height of the nocturnal inversion, and the height of the wind maximum do not in general coincide. Further, the night-to-night variability is often greater than the variability during a single night and there is a tendency of the boundary layer flow to become decoupled from the surface (Garratt, 1996).

Temperature inversion approaches can be a effective means for determining representative or climatological ABL heights based on large data sets. AFTAC's multi-year analysis for the United States using a critical inversion method provides a valuable database for current operational needs. In ARAC emergency response applications, however, this approach may not be robust due to the difficulties in determining the inversion from a single profile, along with the potential lack of representative data due to the infrequency (typically 12 hour intervals for upper air observations) and poor spatial distribution of soundings.

Surface flux based approaches have been extensively used. They are particularly attractive for operational applications because the required parameters can be estimated from readily available surface observations. For the convective boundary layer, the slab model provides a straightforward method for modeling the time evolution of the ABL height.

The use of the Richardson number to diagnose $h_{\mathrm{ABL}}$ is recommended by the European Union COST working group on mixing layer depth (Seibert, 1997), when sufficient wind and temperature profile data are available. It appears to be successful for cases in which the data provides some resolution, but may not resolve details of the ABL structure or the capping inversion. The generalized bulk Richardson number formulation provides a single formula applicable in all stability regimes.

A slab model approach is currently being implemented in the ARAC models, due to its ability to handle limited data problems. An initial investigation of the Richardson number approach has also begun based on the use of weather forecast model data (see Appendix $\mathbf{B}$ ). Data sets are being obtained for testing these approaches to determining $h_{\mathrm{ABL}}$. The work on boundary layer height is proceeding in parallel with the development of three-dimensional eddy diffusivity fields to drive the dispersion model. The completion of a robust operational capability will also require implementation of appropriate land-surface and meteorological data feeds and validation using real world data sets. 


\section{ACKNOWLEDGMENTS}

This work was funded by the Air Force Technical Applications Center and was performed under the auspices of the U.S. Department of Energy by Lawrence Livermore National Laboratory under Contract No. W-7405-ENG-48.

\section{A APPENDIX: SURFACE-LAYER TURBULENCE SCALING PARAMETERS}

A standard approach described by Van Ulden and Holtslag (1985) is available for calculating the surface fluxes and key surface-layer turbulence scaling parameters (friction velocity $u_{*}$, MoninObukhov length $L$ ) using routinely available meteorological and surface characteristics data. The surface heat and momentum fluxes are determined from flux-profile relationships based on surfacelayer similarity theory, a straightforward parameterization of the net radiation using cloud cover, a simple scheme for the soil heat flux, and a modified Priestley-Taylor (1972) formulation to determine latent and sensible heat fluxes. Over land, the minimum inputs required by these methods are

- wind at one height combined with a roughness length (or wind at two heights),

- temperature at one height (high accuracy not required),

- cloud cover fraction,

- solar elevation angle (determined from time of day, latitude, longitude),

- (optionally) short wave radiation.

Over water, the method requires the following inputs :

- wind at one height,

- sea surface temperature,

- temperature at one height,

- (optionally) dew point temperature (if not available, method will still work using a

Priestly-Taylor formulation for the latent heat flux).

The roughness length over water is calculated as a function of the friction velocity.

Estimates are also required for the following surface and soil characteristic parameters: surface roughness length, albedo, the modified Priestley-Taylor parameter, and the bulk soil heat transfer coefficient. Beljaars and Holtslag (1990) discuss methods for estimating these parameters based on terrain type, land use, soil type, and moisture availability. Their software library has been obtained and is being adapted for use in the ARAC models.

\section{B APPENDIX: WEATHER FORECAST MODEL DATA}

ARAC's in-house mesoscale weather forecast model COAMPS (Hodur, 1996) contains a Richard- 
son number diagnostic for $h_{\mathrm{ABL}}$ using a critical value of 0.5. COAMPS also outputs various turbulence fields anư surface fluxes. This data will be used to investigate variants on the bulk Richardson number approach, including the use of the surface friction and temperature excess terms, and to test the method's sensitivity to the choice of critical value. The fields also provide an alternative source of input data for the slab model and will be used for the comparison and evaluation of the $h_{\mathrm{ABC}}$ formulations for various atmospheric stability conditions.

In principle, the $\mathrm{ABL}$ height can be determined by any weather forecast model from the intensity of turbulence as a function of height. However, neither $h_{\mathrm{ABI}}$, or the required turbulent fields are typically provided to ARAC by external model data sources. The temporal and vertical resolution of model data are often insufficient for an accurate determination of the top of the ABL, especially in the case of global models. However, boundary layer and turbulence methods developed for COAMPS can be applied to new model fields as appropriate data is made available. 


\section{REFERENCES}

Beljaars, A.C.M., A.A.M. Holtslag, and R.M. van Wetrhenen,1989: Description of a software library for the calculation of surface fluxes, Technical report TR-112, Royal Netherlands Meteorological Institute

Beljaars, A.C.M. and A.A.M. Holtslag, 1990: A software library for the calculation of surface fluxes over land and sea, Environ. Software 5, 60-68

Beljaars, A. C. M. and A. K. Betts, 1992: Validation of the Boundary Layer Representation in the ECMWF Model, Seminar Proceedings Validation of Models over Europe, Vol II, Reading, UK, 7-11 September 1992

Blackadar, A. K. and H. Tennekes, 1968: Asymptotic similarity in neutral barotropic planetary: boundary layers, J. Atmos. Sci. 25, 1015-1020

Carson, D. J., 1973: The development of a dry inversion-capped convectively unstable boundary layer, J. R. Met. Soc. 99, 450-467

EPA, 1995: A User's Guide for the CALMET Meteorological Model, EPA-454/B-95-002, U.S. Environmental Protection Agency, Research Triangle Park, NC

Garratt, J. R., G. D. Hess, W. L. Physick, and P. Bougeault, 1996: The atmospheric boundary layer - advances in knowledge and application, Boundary-Layer Met. 78, 9-37

Hanna, S. R., 1969: 'The thickness of the planetary boundary layer, Atmos. Envir. 3, 519-536

Heffter, J. L., 1980: Transport Layer Depth Calculations, Second Joint Conference on Applications of Air Pollution Meteorology, New Orleans, LA (1980)

Hodur, R. M., 1996: The Naval Research Laboratory's Coupled Ocean/Atmosphere Mesoscale Prediction System (COAMPS), Mon. Wea. Rev. 125, 1414-1430

Holtslag, A. A. M., E. van Meijgaard, W. C. De Rooy, 1995: A comparison of boundary layer diffusion schemes in unstable conditions over land, Boundary-Layer Met. 76, 69-95

Holzworth, G., 1967: Mixing depths, wind speeds and air pollution potential from selected locations in the United States, J. Appl. Met. 6, 1039-1044

Kienzle, M. , K. Atchinson, and S. Masters, 1985: Worldwide Climatological Maximum Mixed Layer Heights, DCS-ATR-84-74, ENSCO, INC.

Kienzle, M. 1990: Development and Application of the Potential Instability Mixing Depth Estimation Technique (PIMIX), ARS-90-24, ENSCO, INC.

Mahrt, L., 1981: Modeling the depth of the stable boundary-layer, Boundary-Layer Met. 21, 3-19

Nieuwstadt, F. T. M, 1981: The Steady-State Height and Resistance Laws of the Nocturnal Boundary Layer Compared with Cabauw Observations 
Olesen, H. R. and N. Brown, 1992: The OML meteorological preprocessor, MST LUFT-A122, National Environmental Research Institute, Roskilde, Denmark

Priestly, C. H. B. and R. J. Taylor, 1972: On the assessment of surface heat flux and evaporation using large scale parameters, Mon. Wea. Rev. 106, 81-92

Seibert, P., F. Beyrich, S.-E. Gryning, S. Joffre, A. Rasmussen and P. Tercier, Mixing height Determination for Dispersion Modelling, Report of Working group 2 of the COST 710 Action on Pre-processing of Meteorological Data for Dispersion Modelling, European Commission

Sorensen, J. H., A. Rasmussen, and H. Svensmark, 1996: Forecast of Atmospheric Boundary Layer Height Utilized for ETEX Real-time Dispersion Modeling, Phys. Chem. Earth 21, 435-439

Straume, A. G., E. N'D. Kolfi, and K. Nodop, 1998: Dispersion Modeling Using Ensemble Forecasts Compared to ETEX Measurements, J. Appl. Met. 37, 1444-1456

Stull, R. B. and A. G. M. Driedonks 1987: Applications of the transilient turbulence parameterization to atmospheric boundary-layer simulations Boundary-Layer. Met. 40, 209-239

Stull, R. B., 1988: An Introduction to Boundary Layer Meteorology, Kluwer Academic Press, 666pp

Sykes, R. I. et al., 1996: PC-SCIPUFF Version 0.2 Technical Documentation, Titan Corporation, P. O. Box 2229, Princeton, NJ 08543

'Tennekes, H., 1973: A model for the dynamics of the inversion above a convective boundary layer, J. Atmos. Sci., 30, 558-567

Troen, I. and L. Mahrt, 1986: A simple model of the atmospheric boundary layer, Boundary-Layer Met. 37, 129-149

van Dop, H., M. Krol, and B. Holtslag, 1997: A Global Boundary-Layer Height Climatology, The Determination of the Mixing Height - Current Progress and Problems, EURASAP Workshop Proceedings, Risø National Laboratory, Roskilde, Denmark, 1-3 October, 1997

van Ulden, A. P. and A. A. M. Holtslag, 1985: Estimation of Atmospheric Boundary Layer Parameters for Diffusion Applications, J. Clim. and Appl. Met., 24, 1196-1207

Venkatram, A. and J.C. Wyngaard, eds., 1988: Lectures on Air Pollution Modeling, Am. Meteorol. Soc., Boston, $390 \mathrm{pp}$.

Vogelezang, D. H. P, and A. A. M. Holtslag, 1996: Evolution and Model Impacts of Alternative Boundary Layer Height Formulations, Boundary-Layer Met. 81, 245-269

Wetzel, P. J., 1982: Toward Parameterization of the Stable Boundary Layer, J. Appl. Met. 21, 7-13

Wotawa, G., A. Stohl and H. Kromp-Kolb, 1996: Parameterization of the planetary boundary layer over Europe - a data comparison between the observation based OML preprocessor and EMCWF model data, Beitr. Phys. Atmosph. 69, 273-284

Yamada, T., 1979: Prediction of the nocturnal surface inversion height, J. Appl. Met. 18, 526-531

Zilitinkevich, S. S., 1972: On the Determination of the Height of the Ekman Boundary Layer, Boundary-Layer Met. 3, 141-145 